Article

\title{
Microwave-Assisted Improved Extraction and Purification of Anticancer Nimbolide from Azadirachta indica (Neem) Leaves
}

\author{
Panawan Suttiarporn ${ }^{1}$ and Vachira Choommongkol ${ }^{2, *}$ \\ 1 Faculty of Science, Energy and Environment, King Mongkut's University of Technology North Bangkok, \\ Rayong Campus 21120, Thailand; panawan.s@sciee.kmutnb.ac.th \\ 2 Department of Chemistry, Faculty of Science, Maejo University, Chiang Mai 50290, Thailand \\ * Correspondence: vachira@mju.ac.th
}

Academic Editor: Soran Maria Loredana

Received: 27 May 2020; Accepted: 22 June 2020; Published: 24 June 2020

\begin{abstract}
Nimbolide, a limonoid present in leaves of the neem tree (Azadirachta indica), is an anticancer compound against a panel of human cancer cell lines. The rapid process of extraction and purification of the nimbolide from the leaves of neem tree through microwave-assisted extraction (MAE) coupled with a chromatographic technique was accomplished. The crude with a maximum content of nimbolide could be recovered from neem leaves through MAE. By using three-factors, three-level Box-Behnken design of response surface methodology (RSM), the optimal conditions for nimbolide extraction $\left(R^{2}=0.9019\right)$ were solid/liquid ratio $1: 16 \mathrm{~g} / \mathrm{mL}$, microwave power $280 \mathrm{~W}$, and extraction time $22 \mathrm{~min}$. The enriched extract was further purified by a preparative thin-layer chromatography (PTLC), where nimbolide was obtained as $0.0336 \mathrm{~g}(0.67 \%$ yield, purity over $98 \%)$ with ethyl acetate/hexane $=4: 6$ in $3.0 \mathrm{~h}$. Structural elucidation was performed through spectroscopic techniques, including FT-IR, ${ }^{1} \mathrm{H}$, and ${ }^{13} \mathrm{C}-\mathrm{NMR}$. This method was simple and had a good potential for the purification of bioactive compounds from a natural product.
\end{abstract}

Keywords: nimbolide; Azadirachta indica; optimization; response surface methodology; microwave-assisted extraction

\section{Introduction}

Azadirachta indica A. Juss belongs to the family Meliaceae, and is commonly known as "neem". The neem tree, an extraordinary plant, is reported to be a tree that can solve global problems, by the US National Academy of Science [1]. The neem is cultivated in the Indian subcontinent and other regions of the world in at least 30 countries ranging from Asia to Africa, and as far as America [2]. Almost all parts of the plant, including leaves, flowers, fruits, seeds, and bark are extensively used in traditional medicine for treating various human diseases [3,4].

Neem is one of the richest sources of biologically active secondary metabolites, particularly tetranortriterpenoids or limonoids, such as azadirachtin, nimbolide, nimbin, salannin, nimbidin, and gedunin [5,6]. Among the limonoid compounds, nimbolide, as shown in Figure 1, is the major active constituent present in the leaves of Azadirachta indica [7]. The nimbolide was reported to be an "anticancer compound" as it showed promising anticancer activities against a variety of human cancer types, including breast cancer, cervical cancer, choriocarcinoma, colon cancer, pancreatic cancer, and prostate cancer $[8,9]$. Moreover, the compound shows therapeutic properties like antimalarial activity [3], antibacterial activity [10], antifeedant [11], and antioxidant [12].

Recently, there has been an increasing demand for plant bioactive substances that can be used as functional ingredients in pharmaceutical and nutraceutical products due to their multitarget therapeutic 
properties, with minimal or no undesirable side-effects [13]. There is a rise in interest in the potential use of the nimbolide constituent as an anti-cancer drug [8].

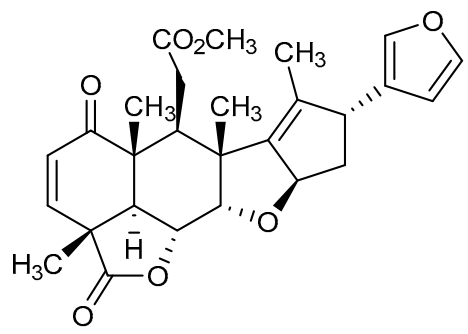

Figure 1. Chemical structure of nimbolide.

Selection of a proper extraction method to isolate bioactive compounds should be a key consideration due to sample preparation, the first step in the analysis of any medicinal plant study, and the important role it plays on the final outcome. Biologically active substances from the neem tree are mainly extracted using traditional techniques, such as maceration [14] and heating reflux extraction [15]. However, these methods are time-consuming and laborious. The supercritical fluid extraction, as an alternative method, is also reported for the separation of nimbolide from neem leaves (Azadirachta indica) [16]. A new approach, microwave-assisted extraction (MAE), is a powerful technique for isolating bioactive substances from a medicinal plant and it has a number of advantages, such as a higher extraction rate, supreme product quality at a lower cost, requiring considerably less time, and consuming a smaller amount of solvent [17]. MAE was successfully used in extraction protocols for the effective isolation of limonoid, azadirachtin [18], and neem oil [19], from neem.

However, the extraction efficiency of biologically active compounds using the MAE process is influenced by various extraction conditions, such as extraction time, microwave power, the ratio of material-to-solvent, among others, and their effects might be either independent or interactive [20]. To overcome this problem, response surface methodology (RSM), a powerful multivariate statistical and mathematical tool was applied for optimizing the conditions of a complex experimental process. RSM has been successfully utilized for developing and optimizing various extraction processes from plants, to yield bioactive compounds like 1,8-cineole [21], zeaxanthin and lutein [22], total phenolic compounds and flavonoids [23], and polysaccharide [24].

To the best of our knowledge, there are no studies that have focused on the optimization of the MAE procedure using RSM and the systematic study for sequence extraction and purification of nimbolide from Azadirachta indica (Neem) leaves. Therefore, the objective of this study was to reveal a simple method for the isolation and purification of nimbolide from Azadirachta indica (Neem) leaves. The RSM method was applied to investigate the optimal MAE process for the separation of enriched nimbolide extract from Azadirachta indica (Neem) leaves, based on quantitative evaluation, using high-performance liquid chromatography (HPLC). After RSM optimization, the extract was further purified to obtain high purity of nimbolide using a simple preparative thin-layer chromatography (PTLC).

\section{Results and Discussion}

\subsection{HPLC Quantification Method Validation}

The method revealed a good linearity in the range of nimbolide concentration $(0.25$ to $200 \mu \mathrm{g} / \mathrm{mL})$. The analytical curve generated a linear equation $(y=16488 x-11479)$ with a determination coefficient $\left(\mathrm{R}^{2}\right)$ of 0.9999 . The LOD is the lowest detectable concentration of nimbolide in the MAE extract but it is not quantified as the exact content. Meanwhile, the LOQ, the lowest concentration of nimbolide in the MAE extract could be accurately and precisely measured. The LOD and LOQ of the analytical procedure were $0.02 \mu \mathrm{g} / \mathrm{mL}$ and $0.07 \mu \mathrm{g} / \mathrm{mL}$, respectively. The precision data were represented by the relative standard deviation (RSD) calculated from the ratio between the standard deviation of data $(n=10)$ and the mean of the nimbolide content. The coefficient of variation (\%RSD) value for the 
content of nimbolide in repeatability test was $1.46 \%$. The RSD value between the data of two different days was $2.58 \%$. The quantification procedure was precise, as indicated by the low RSD value (less than 5\%) recommended by ANVISA [25]. The recovery value of nimbolide was $101.87 \%$ and RSD was $1.84 \%$, which indicated that the quantification method had sufficient accuracy.

\subsection{Screening of Single Variables}

The solvent selection is one of the most essential steps in bioactive compound extraction from plants [26] and affects microwave extraction. The high ability to absorb microwave power leads to the high ability to dissolve the compounds of interest. To yield the maximum amount of target compound, the MAE process could be performed with an appropriate solvent that has a high capacity to absorb microwave irradiation and convert the energy into heat, which depends on the solvent dielectric properties, based on the polarity of the target compound [27]. Thus, the extracted solvent (methanol, ethanol, dichloromethane, ethyl acetate, and hexane) was first selected and judged, based on extraction efficiency and operational performance. Figure $2 \mathrm{~A}$ showed that the amount of nimbolide of Azadirachta indica varied from $841.07 \pm 50.91$ to $3.289 .52 \pm 85.91 \mu \mathrm{g} / \mathrm{g}$ weight extract/weight of dried plant material, with a descending order of ethanol $(3,289.52 \pm 85.91 \mu \mathrm{g} / \mathrm{g})>$ dichloromethane $(1,314.82 \pm 49.05 \mu \mathrm{g} / \mathrm{g})>$ hexane $(1,042.05 \pm 89.83 \mu \mathrm{g} / \mathrm{g})>$ methanol $(1,040.25 \pm 85.06 \mu \mathrm{g} / \mathrm{g})>$ ethyl acetate $(841.07 \pm 50.91 \mu \mathrm{g} / \mathrm{g})$. The result revealed that the highest nimbolide yield was obtained by ethanol as a solvent, as compared to other solvents. This was due to an affinity between the polarity of the solvent and the compound of interest [28]. The high extraction efficiency of ethanol was due to the high solubility of the limonoid group in alcohol [29]. It was consistent with previous reports that ethanol is a good solvent system for the extraction of polyphenolic compounds from Ocimum basilicum [30]. Thus, ethanol was the most appropriate solvent in extraction processes, not only due to its extraction efficiency but also because of its safety for human consumption and environment.
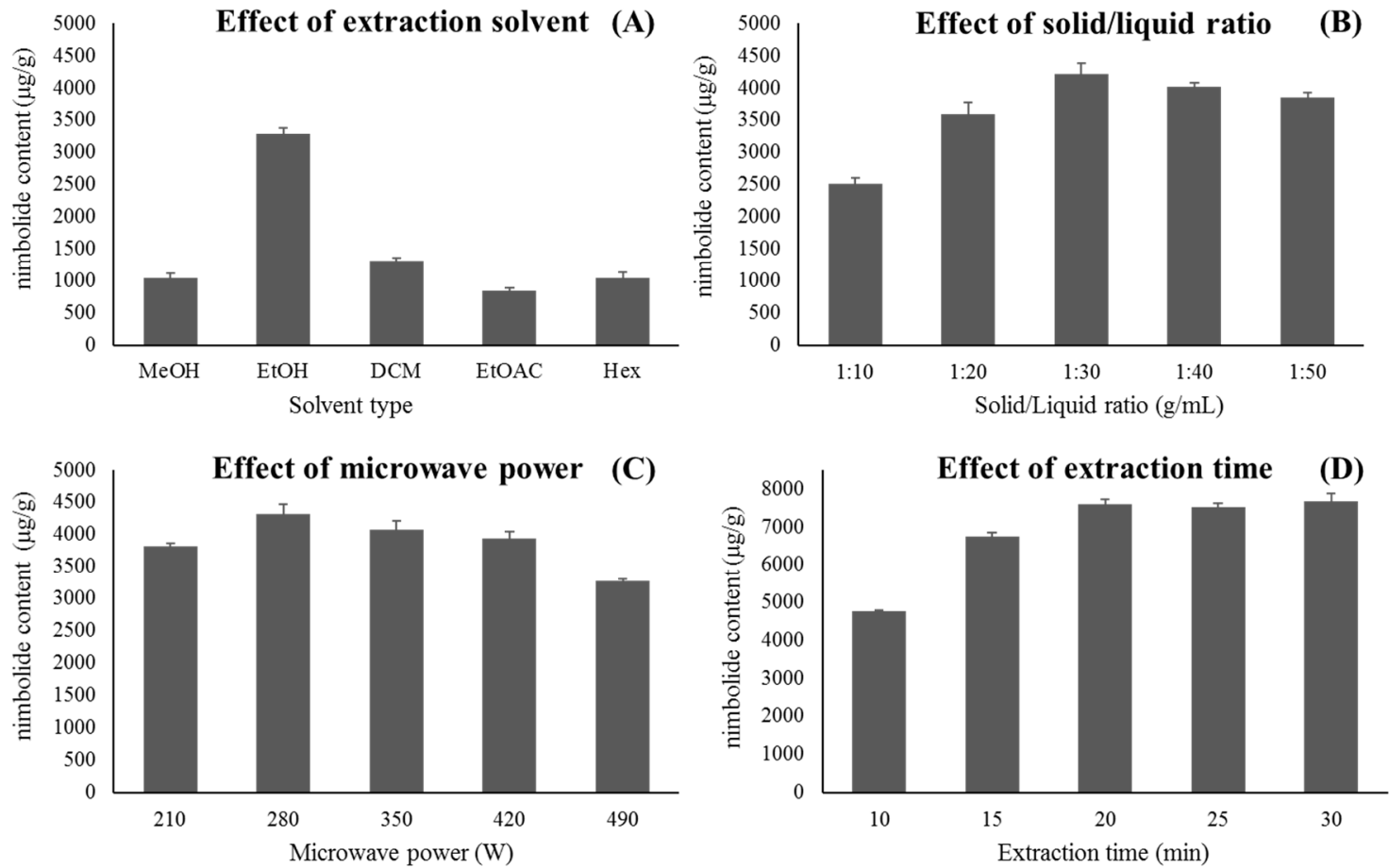

Figure 2. Effect of (A) extraction solvent, (B) solid/liquid ratio, (C) microwave power, and (D) extraction time on the nimbolide content.

The optimization by RSM was more effective when an appropriate range of parameters was chosen. The selection of condition ranged for the MAE, the material/solvent ratio, microwave power, and microwave time, before setting the levels of the studied factors that were also investigated by 
single factor experiment and the levels of the MAE studied parameters. For a single factor experiment of MAE parameters, one factor was changed in a certain range, while the remaining factors were kept constant. In Figure 2B, the solid/liquid ratio was varied from 1:10 to 10:50 g/mL, with microwave power at $210 \mathrm{~W}$ and extraction time at $10 \mathrm{~min}$. The results indicated that the highest nimbolide content was obtained at the solid/liquid ratio $1: 30 \mathrm{~g} / \mathrm{mL}(4211.17 \pm 177.11 \mu \mathrm{g} / \mathrm{g}$ dry weight $)$. In liquid-solid extraction, a higher volume of extraction solvent would increase the number of target compounds until equilibrium was reached [31]. Moreover, a larger volume of solvent would cause more absorption of microwave irradiation, to ensure rapid heating up, leading to an enhanced extraction efficiency [32]. However, at an equilibrium state, where the amount of target analyte in the material was exhausted, the higher volume of the solvent would not promote the nimbolide content any longer [31]. Hence, 1:10-1:50 g/mL was selected as an appropriate range of solid/liquid ratio for further optimization.

In Figure 2C, microwave power was surveyed from $210-490 \mathrm{~W}$ with a solid/liquid ratio at $1: 30 \mathrm{~g} / \mathrm{mL}$ and extraction time at $10 \mathrm{~min}$. As the irradiation increased from $210-280 \mathrm{~W}$, the nimbolide content increased from $3811.98 \pm 47.68$ to $4323.95 \pm 153.15 \mu \mathrm{g} / \mathrm{g}$ dry weight. By continuing to increase the microwave power, the content of the compound was reduced. The microwave power and thermal effect for the extraction process were interrelated, as a high microwave power increased the temperature in the system [33]. However, high temperature might lead to its degradation due to the thermally labile property of nimbolide in limonoid group [29]. Therefore, 210-490 W was chosen for subsequent experimental design by the Box-Behnken design (BBD).

Finally, the effect of extraction time on the content of nimbolide was studied in the range of 10-30 min with a solid/liquid ratio at 1:30 g/mL $280 \mathrm{~W}$ and a microwave power at $210 \mathrm{~W}$ (Figure 2D). The results showed that, when the extraction time increased from 10 to $20 \mathrm{~min}$, the nimbolide content increased from $4758.44 \pm 41.29$ to $7600.86 \pm 135.37 \mu \mathrm{g} / \mathrm{g}$ dry weight. By continuing to increase irradiation time to $30 \mathrm{~min}$, the nimbolide content increased slightly to $7670.93 \pm 209.98 \mu \mathrm{g} / \mathrm{g}$ dry weight. However, the different nimbolide contents that were achieved at 20, 25, and 30 min were not statistically significant. The prolonged time-period past a certain point, did not affect the nimbolide content, due to an eventual equilibrium between the material solute and solvent [34]. Therefore, 10-30 min was selected for further studies.

\subsection{Response Surface Model Fitting}

To achieve the highest content of the bioactive nimbolide compound, the Box-Behnken design (BBD) was utilized to further optimize the MAE parameters, including the solid/liquid ratio (1:10-1:50 g/mL), microwave power (210-490 W), and extraction time (10-30 min). The BBD was chosen, as it required a fewer number of runs. Table 1 presented the treatments with the encoded levels of variables and the experimental results of the nimbolide content. Fifteen experiments were designated with random 12 factorial experiments and 3 zero-point tests, to estimate the errors. The investigated response of 15 varied MAE conditions was analyzed through HPLC. Regression analysis of the nimbolide prediction study was employed to fit full second-degree polynomial model, including linear $\left(X_{1}, X_{2}\right.$ and $\left.X_{3}\right)$, quadratic $\left(X_{1}^{2}, X_{2}^{2}\right.$ and $\left.X_{3}^{2}\right)$, and interaction $\left(X_{1} X_{2}, X_{1} X_{3}\right.$ and $\left.X_{2} X_{3}\right)$ at $5 \%$ level of significance. The analysis of variance (ANOVA) results for the regression equation are presented in Table 2. The model sufficiently fitted the data because due to the low $p$-value $(p<0.05)$, high $F$-values, and no significant lack of fit $(p>0.05)$. Furthermore, the model coefficients of determination $\left(\mathrm{R}^{2}\right)$ value for the model was $90.19 \%$, which was higher than $80 \%$ (>0.80), indicating that more than $90.19 \%$ of the response variability could be described by the experimental data. 
Table 1. The Box-Behnken experimental design with the encoded microwave-assisted extraction (MAE) conditions and the analytically obtained values of the nimbolide content.

\begin{tabular}{ccccc}
\hline Std. Order & $\begin{array}{c}\mathbf{X}_{\mathbf{1}} \\
\text { Solid/Liquid Ratio } \\
(\mathbf{g} / \mathbf{m L})\end{array}$ & $\begin{array}{c}\mathbf{X}_{\mathbf{2}} \\
\text { Microwave Power } \\
(\mathbf{W})\end{array}$ & $\begin{array}{c}\mathbf{X}_{\mathbf{3}} \\
\text { Extraction Time } \\
(\mathbf{m i n})\end{array}$ & $\begin{array}{c}\text { Nimbolide Content } \\
(\boldsymbol{\mu} \mathbf{g} / \mathbf{g} \mathbf{D W})\end{array}$ \\
\hline 12 & $1: 30$ & 490 & 30 & 3517.25 \\
2 & $1: 50$ & 210 & 20 & 2858.00 \\
9 & $1: 30$ & 210 & 10 & 2869.30 \\
7 & $1: 10$ & 350 & 30 & 4058.00 \\
1 & $1: 10$ & 210 & 20 & 5786.00 \\
8 & $1: 50$ & 350 & 30 & 3092.88 \\
10 & $1: 30$ & 490 & 10 & 2395.62 \\
11 & $1: 30$ & 210 & 30 & 2932.52 \\
6 & $1: 50$ & 350 & 10 & 5589.84 \\
14 & $1: 30$ & 350 & 20 & 5620.12 \\
3 & $1: 10$ & 490 & 20 & 3837.01 \\
4 & $1: 50$ & 490 & 20 & 5069.62 \\
15 & $1: 30$ & 350 & 20 & 2993.05 \\
5 & $1: 10$ & 350 & 10 & 5208.87 \\
\hline 13 & $1: 30$ & 350 & 20 & \\
\hline
\end{tabular}

Table 2. Analysis of variance (ANOVA) for the response surface quadratic model of the nimbolide content.

\begin{tabular}{cccccc}
\hline Source & $\begin{array}{c}\text { Sum of } \\
\text { Squares }\end{array}$ & $\begin{array}{c}\text { Degrees of } \\
\text { Freedom }\end{array}$ & Mean Square & $\boldsymbol{F}$-Value & $p$-Value \\
\hline Model & 21429495 & 9 & 2381055 & 5.11 & 0.044 \\
Linear & 1599763 & 3 & 533254 & 1.14 & 0.417 \\
$\mathrm{X}_{1}$ & 9535 & 1 & 9535 & 0.02 & 0.892 \\
$\mathrm{X}_{2}$ & 1519380 & 1 & 1519380 & 3.26 & 0.131 \\
$\mathrm{X}_{3}$ & 70847 & 1 & 70847 & 0.15 & 0.713 \\
Square & 10344886 & 3 & 3448295 & 7.39 & 0.028 \\
$\mathrm{X}_{1}^{2}$ & 1162319 & 1 & 1162319 & 2.49 & 0.175 \\
$\mathrm{X}_{2}^{2}$ & 6392946 & 1 & 6392946 & 13.71 & 0.014 \\
$\mathrm{X}_{3}^{2}$ & 4109850 & 1 & 4109850 & 8.81 & 0.031 \\
$2-$ Way & 9484847 & 3 & 3161616 & 6.78 & 0.033 \\
Interaction & 7563935 & 1 & 7563935 & 16.22 & 0.010 \\
$\mathrm{X}_{1}^{*} \mathrm{X}_{2}$ & 1640850 & 1 & 1640850 & 3.52 & 0.120 \\
$\mathrm{X}_{1}^{*} \mathrm{X}_{3}$ & 280062 & 1 & 280062 & 0.60 & 0.473 \\
$\mathrm{X}_{2}^{*} \mathrm{X}_{3}$ & 2167721 & 3 & 722574 & 8.82 & 0.104 \\
Lack-of-Fit & 163856 & 2 & 81928 & & \\
Pure Error & 23761073 & 14 & & & \\
Total & 90.19 & $\mathrm{R}^{2}($ adj) & 72.52 & & \\
$\mathrm{R}^{2}$ & & & &
\end{tabular}

Moreover, the quadratic term of the microwave power $\left(X_{2}\right)$ and the extraction time $\left(X_{3}\right)$ also had a significant influence, indicating that the interrelation between the nimbolide content response variable and the MAE test variable was not linear. Thus, the developed model could be used for the MAE process optimization. The relationship between the response and the MAE independent variables was generated into the second-order polynomial Equation (1), as follows:

$$
Y=5300+35 X_{1}-436 X_{2}+94 X_{3}-516 X_{1}^{2}-1316 X_{2}^{2}-1055 X_{3}^{2}+1375 X_{1} X_{2}-640 X_{1} X_{3}+265 X_{2} X_{3}
$$

where $\mathrm{Y}$ is the nimbolide content, $\mathrm{X}_{1}$ is the solid/liquid ratio, $\mathrm{X}_{2}$ is the microwave power, and $\mathrm{X}_{3}$ is the extraction time 


\subsection{Influence and Optimization of the MAE Parameters on the Nimbolide Content}

The three-dimensional response surface and two-dimensional contour plots shown in Figure 3 were used for not only investigating the optimum values but also for visualizing the effects of the mutual interactions of extraction parameters on the nimbolide content response. The interaction between the solid/liquid ratio $\left(X_{1}\right)$ and the microwave power $\left(X_{2}\right)$ had a statistically significant effect $(p<0.05)$ on the nimbolide content. The nimbolide yield significantly increased with increasing microwave power from 210-280 W, while a further increase in microwave power led to a decrease in the nimbolide content. On the other hand, at a given microwave power, nimbolide yield increased while increasing the extraction time to about $22 \mathrm{~min}$. The increments in the nimbolide yield occurred due to the interaction between microwave power and extraction time. The negative influence of microwave power on nimbolide yield was due to the rapid temperature increase, as excessive irradiation could cause thermal decomposition, while the positive influence could accelerate destruction of the plant cells [35]. The maximum response value was obtained by showing the response surface plots and contour plots as the red area. The optimum selected MAE conditions were a solid/liquid ratio of 1:16 $\mathrm{g} / \mathrm{mL}$, microwave power $280 \mathrm{~W}$, and an extraction time of $22 \mathrm{~min}$. The maximum nimbolide content of $7046.00 \mu \mathrm{g} / \mathrm{g}$ dry weight was forecasted by the second-order polynomial model for enriching the nimbolide extraction. Determination of optimum conditions and the predicted value was based on desirability 0.9174 . 

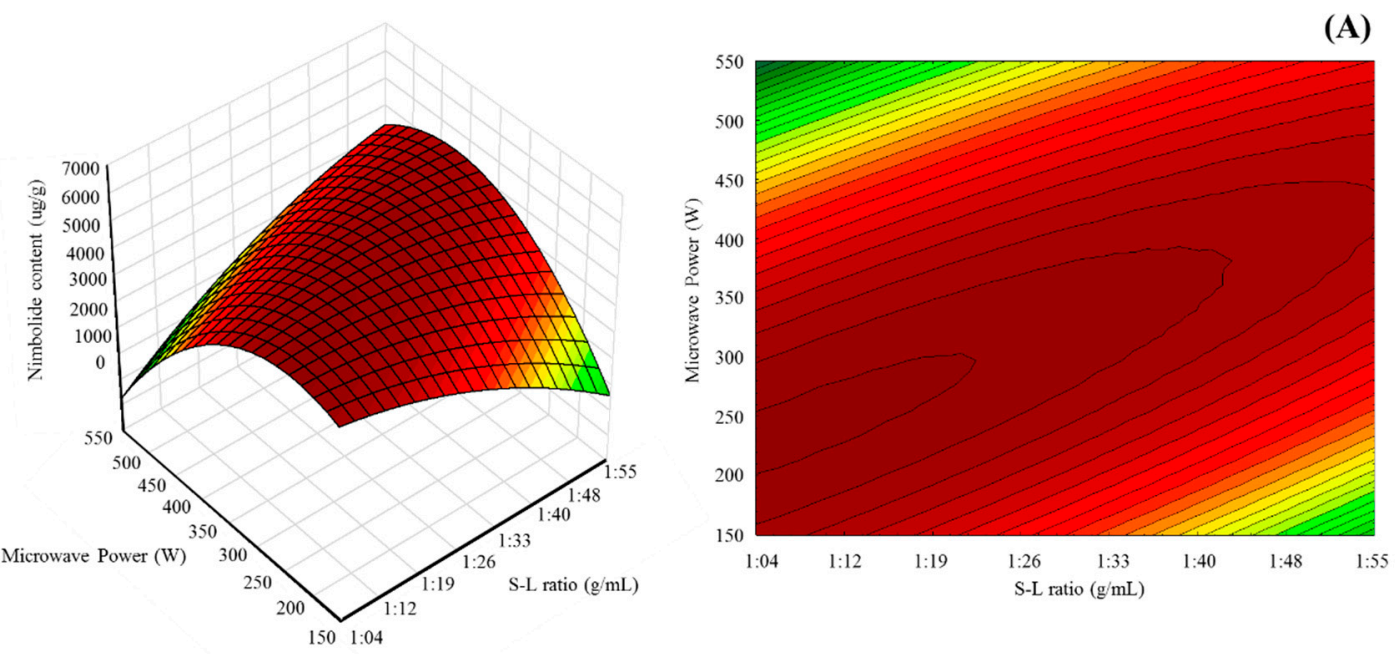

(B)
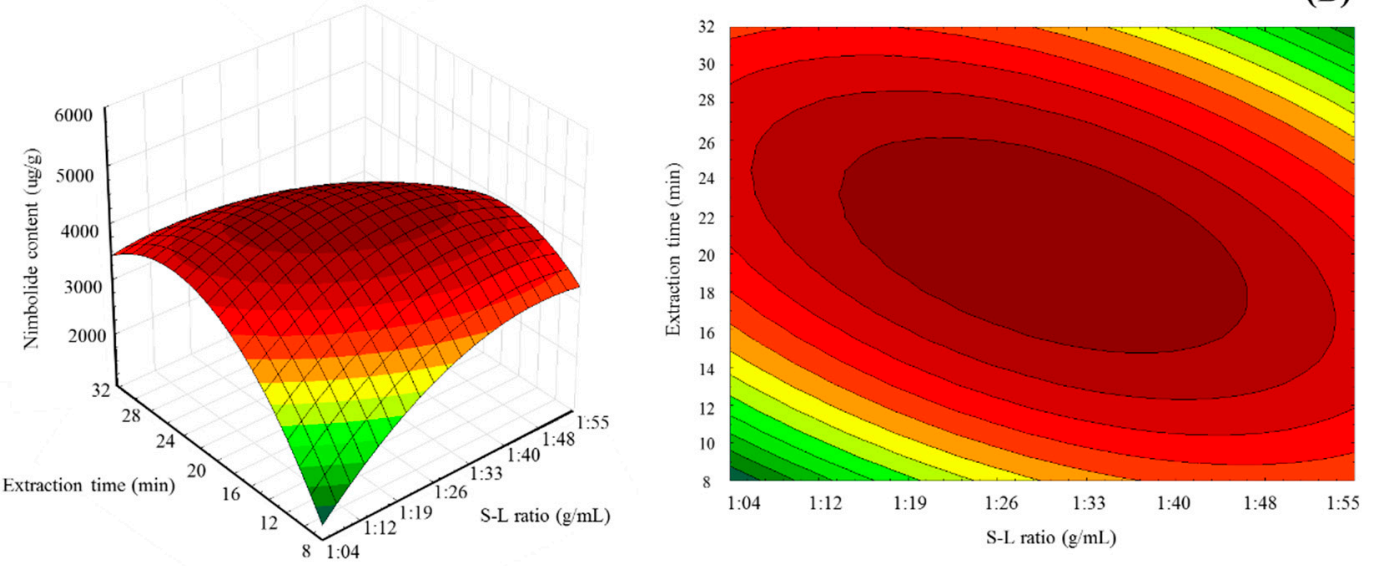

(C)
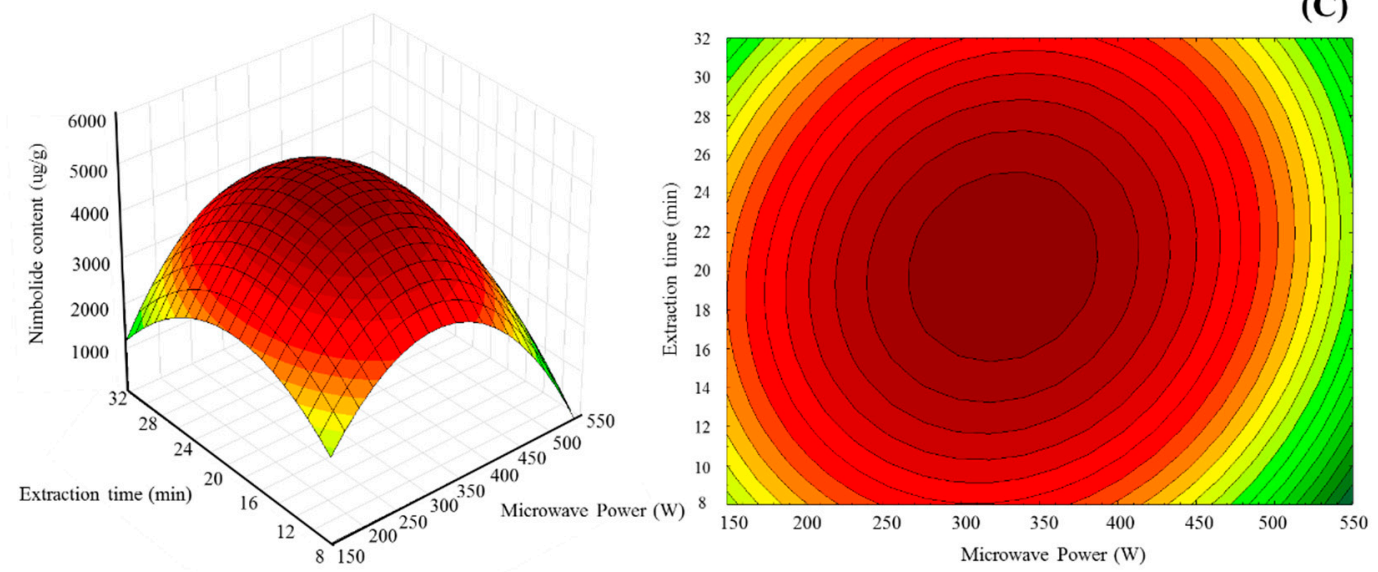

Figure 3. Three-dimensional and contour plots showing the effect of $(\mathbf{A})$ solid/liquid ratio $\left(\mathrm{X}_{1}\right)$ and microwave power $\left(X_{2}\right) ;(B)$ solid/liquid ratio $\left(X_{1}\right)$ and extraction time $\left(X_{3}\right)$; and $(C)$ microwave power $\left(X_{2}\right)$ and extraction time $\left(X_{3}\right)$.

\subsection{Verification of the Predictive Model}

To validate the predicted nimbolide content, the actual experiment of the microwave-assisted extraction was performed under optimal conditions. The results of the validated MAE extraction conditions (Table 3) showed that the actual content of nimbolide was closed to those predicted by the models with $2.80 \%$ error. This confirmed that the constructed response model was adequate in predicting the nimbolide content. 
Table 3. Verification of the predicted value at the optimal extraction condition.

\begin{tabular}{ccc}
\hline Variables and Response & Predicted Value & Actual Result \\
\hline $\mathrm{X}_{1}$ solid/liquid ratio $(\mathrm{g} / \mathrm{L})$ & $1: 16.45$ & $1: 16$ \\
$\mathrm{X}_{2}$ Microwave power $(\mathrm{W})$ & 280.71 & 280 \\
$\mathrm{X}_{3}$ Time (min) & 21.91 & 22 \\
\hline Nimbolide (mg/g dry weight) & 7.046 & $7.243 \pm 0.150$ \\
Nimbolide isolated (mg/g dry & - & $6.720 \pm 0.500$ \\
weight) & &
\end{tabular}

\subsection{Purification, Determination, and Characterization of Nimbolide}

Neem leaf powder $(5.00 \mathrm{~g})$ was extracted by MAE using the optimum selected MAE conditions. The solution was filtered and evaporated to dryness. The crude extract was dissolved with dichloromethane (DCM) to give the DCM crude extract. The crude product was successfully purified by preparative thin-layer chromatography (PTLC; silica gel), using EtOAc/hexane $=4: 6$ as an eluent to give a nimbolide-enriched fraction, which was further subjected to repeated purification by PTLC, to afford a high yield of nimbolide ( $0.0336 \mathrm{~g}, 0.67 \%$ yield). A good separation of nimbolide from other compounds occurred in $3.0 \mathrm{~h}$. with microwave-assisted improved extraction, combined with a simple chromatographic technique. In comparison to conventional extraction methods, there was a considerable improvement of the nimbolide yield, which was consistent with previous reports (Table 4), as microwave irradiation can cause explosion of neem leaf structures inside the sample, releasing the nimbolide to the environment. However, Dai, J. et al. suggested that it could be carried out only in plant materials possessing relatively weak microstructures [18]. Moreover, RSM was supported to achieve the maximum nimbolide yield obtained from the MAE procedure.

Table 4. The content of the isolated nimbolide obtained from several extraction methods.

\begin{tabular}{cccccc}
\hline Material & $\begin{array}{c}\text { Extractions } \\
\text { Technique }\end{array}$ & $\begin{array}{c}\text { Purification } \\
\text { Technique }\end{array}$ & $\begin{array}{c}\text { Nimbolide } \\
\text { Isolated (g) }\end{array}$ & \% Yield & Author \\
\hline $\begin{array}{c}\text { Dried-leaves } \\
(5 \mathrm{~g})\end{array}$ & $\begin{array}{c}\text { optimal condition } \\
\text { MAE } \\
(\text { Ethanol })\end{array}$ & $\begin{array}{c}\text { Silica gel } \\
(\text { PTLC) }\end{array}$ & $0.0336 \mathrm{~g}$ & 0.67 & This study \\
\hline $\begin{array}{c}\text { Reflux } \\
\text { Dried-leaves }\end{array}$ & $\begin{array}{c}\text { (Soxhlet apparatus in } \\
\text { DCM })\end{array}$ & $\begin{array}{c}\text { Silica gel } \\
(\text { CC })\end{array}$ & $0.133 \mathrm{~g}$ & 0.027 & Kigodi, P. G. et al. [36] \\
\hline $\begin{array}{c}\text { Deflux } \\
(545 \mathrm{~g})\end{array}$ & $\begin{array}{c}\text { (Soxhlet apparatus in } \\
\text { hexane })\end{array}$ & $\begin{array}{c}\text { Silica gel } \\
(\text { CC })\end{array}$ & $0.716 \mathrm{~g}$ & 0.13 & Nair, M. S. et al. [37] \\
\hline $\begin{array}{c}\text { Dried-leaves } \\
(500 \mathrm{~g})\end{array}$ & $\begin{array}{c}\text { Maceration } \\
\text { (acetone) }\end{array}$ & $\begin{array}{c}\text { Silica gel } \\
(\text { CC })\end{array}$ & $0.45 \mathrm{~g}$ & 0.09 & Dhanya, S. et al. [38] \\
\hline
\end{tabular}

\section{Materials and Methods}

\subsection{Materials and Apparatus}

Fresh leaves of neem (Azadirachta indica A. Juss) were collected from the Sansai, Chiang Mai Province in Thailand in February 2016. The plant was identified from the CMUB Herbarium, Chiang Mai University (Specimen voucher No. 39898). The leaves were air-dried and ground with a commercial grinder and stored at room temperature, until further analysis.

The solvents used for extraction in commercial grade (methanol, ethanol, ethyl acetate, dichloromethane, and hexane) were distilled before use. Nimbolide (CAS: 25990-37-8) was purchased from Sigma-Aldrich (St. Louis, MO, USA). Water and methanol in HPLC grade were purchased from RCI labscan (Bangkok, Thailand). 


\subsection{Microwave-Assisted Extraction (MAE) Procedure of the Enriched Nimbolide}

MAE experiments were performed using an Electrolux EME2024MW system (Electrolux, Bangkok, Thailand) equipped with a reflux apparatus. Powder of neem leaf was accurately weighed, placed into a sampling flask, and operated with MAE, using different solvent and different MAE conditions. The filtered solutions were diluted 10 -fold, with a suitable solvent, and were filtered through $0.45-\mu \mathrm{m}$ pore nylon syringe filter before analysis using a high-performance liquid chromatography.

\subsection{Quantification of Nimbolide Content Using HPLC Analysis and Method Validation}

Quantitative analysis of nimbolide in neem leaves extracts was performed by PerkinElmer Flexar ${ }^{\mathrm{tm}}$ HPLC equipped with photodiode array detector (PAD) detector (PerkinElmer, Waltham, MA, USA). The separation was performed on a reversed-phase Brownlee C18 column $(4.6 \mathrm{~mm}, 250 \mathrm{~mm}, 5 \mu \mathrm{m}$, PerkinElmer, Waltham, MA, USA) at $35^{\circ} \mathrm{C}$. A mobile phase was a mixture of methanol and water in a ratio of 70:30 $(v / v)$ used in an isocratic elution system. The flow rate of mobile phase was set at $1 \mathrm{~mL} / \mathrm{min}$. The injection volume was $10 \mu \mathrm{L}$. The detector wavelength of nimbolide was monitored at $217 \mathrm{~nm}$. Peak identification was done by comparison of retention times of standard compound. Standard calibration curves were prepared by serially diluting the stock solutions of nimbolide in ethanol to yield concentrations of $0.25-200 \mu \mathrm{g} / \mathrm{mL}$, with a correlation coefficient $\left(\mathrm{R}^{2}\right)$ of 0.9999 . All controlled instrument and data analysis/processing were performed via the PerkinElmer Chromera ${ }^{@}$ CDS software.

HPLC quantification of nimbolide was validated for linearity, LOD, LOQ, precision, and accuracy. The linearity was evaluated by the external calibration curve of nimbolide at seven concentration levels of the nimbolide standard $(0.25,0.50,1.00,5.00,12.50,25.00,50.00,100.00$, and 200.00 $\mu \mathrm{g} / \mathrm{mL})$. The analysis was carried out in triplicate, for each test concentration, and subjected to the HPLC system. The analytical curve was fitted by linear regression and the determination coefficients were calculated. The limit of detection (LOD) and limit of quantification (LOQ) were investigated based on the standard deviation (SD) of the intercept with $y$-axis and the slope of calibration (S) of the nimbolide standard curve. Repeatability (intraday) and intermediate precision (interday) were performed. The relative standard deviation (RSD) was calculated, obtained from ten injections. The accuracy of the quantification procedure was evaluated by the recovery analysis.

\subsection{Screening of Single Variables}

Various parameters had an effect on the extraction process. The extraction factors that influenced the MAE process were solvent nature, extraction time, microwave power, and material/solvent ratio. Among these parameters, the extraction solvent was optimized as an initial step. Selection of solvents; to evaluate the solvent efficiency, methanol $(\mathrm{MeOH})$, ethanol $(\mathrm{EtOH})$, dichloromethane (DCM), ethyl acetate (EtOAc), and hexane (Hex), were employed as the extraction solvent, based on extraction efficiency and operational performance as an initial step. Furthermore, an appropriate condition ranges of the MAE; extraction time, microwave power, and solid/liquid ratio were studied by a single factor experiment. For the MAE single factor experiment, one factor was varied in a certain range while all other factors were kept constant. The extraction parameters were solid/liquid ratio (1:10, 1:20, 1:30, $1: 40$, and 1:50 g/mL), microwave power $(210,280,350,420$, and $490 \mathrm{~W})$, and extraction time $(10,15,20$, 25 , and $30 \mathrm{~min})$. The nimbolide content was expressed as mean \pm standard deviation (SD) for three replicates. The experiments were investigated for establishing an appropriate range of independent variables in RSM.

\subsection{Experimental Design}

Operational parameters—solid/liquid ratio $\left(X_{1}\right)$, microwave power $\left(X_{2}\right)$, and extraction time $\left(X_{3}\right)$ under different MAE conditions were optimized by the maximized nimbolide content, using a response surface designed experiment combined with a Box-Behnken design (BBD). The input independent variables were coded at three levels $(-1,0,+1)$. The encoded levels of the variables used 
in the experimental design are presented in Table 5. The complete design contained 15 experiment points with 3 replications at the center. Regression analysis was performed on the data obtained by triplicate analysis for each dependent variable, using the Minitab statistics software (trial version 18, Minitab Inc., State College, PA, USA). Experimental data were fitted for maximum nimbolide content, using a second-order polynomial expressed by Equation (2), as follows:

$$
Y=\beta_{0}+\sum_{i=1}^{3} \beta_{i} X_{i}+\sum_{i=1}^{3} \beta_{i i} X_{i}^{2}+\sum_{i=1}^{2} \sum_{j=i+1}^{3} \beta_{i j} X_{i} X_{j}+\varepsilon
$$

where " $Y$ " is the nimbolide response; $X_{i}$ represents the independent variables; the terms $X_{i} X_{j}$ and $X_{i}^{2}$ denote the quadratic and interaction terms, respectively; " $\beta_{0}$ " is the equation parameters for the constant term, " $\beta_{\mathrm{i}}$ " is the linear regression coefficients, " $\beta_{\mathrm{ii}}$ " is the quadratic regression coefficient, " $\beta_{\mathrm{ij}}$ " is the interaction regression coefficient, and " $\varepsilon$ " is the random error.

Table 5. The factors and levels of the Box-Behnken design of the microwave-assisted extraction process of nimbolide from neem.

\begin{tabular}{cccc}
\hline \multirow{2}{*}{ Independent Variable } & \multicolumn{3}{c}{ Level } \\
\cline { 2 - 4 } & $\mathbf{- 1}$ & $\mathbf{0}$ & $\mathbf{+ 1}$ \\
\hline $\mathbf{X}_{\mathbf{1}}$ Solid/Liquid ratio $(\mathrm{g} / \mathrm{mL})$ & $1: 10$ & $1: 30$ & $1: 50$ \\
\hline $\mathbf{X}_{\mathbf{2}}$ Microwave power $(\mathrm{W})$ & 210 & 350 & 490 \\
\hline $\mathbf{X}_{\mathbf{3}}$ Extraction time $(\mathrm{min})$ & 10 & 20 & 30 \\
\hline
\end{tabular}

The data from the BBD model was also applied for prediction of the optimum extraction parameters through response surface analysis. The optimum conditions settings that would yield the maximum nimbolide content, their combined desirability, and prediction of the nimbolide content was generated by the Minitab software optimizer. Three-dimensional and contour plots were constructed using the Statistica program (Trial version 10.0, Statsoft Inc., Tulsa, OK, USA).

\subsection{Verification of the Predictive Model}

The adequacy of the optimized experimental MAE conditions in the MAE process were verified by reproducing the experiment in three replicates with the achieved optimal parameters. The actual nimbolide yield was validated by comparing the predicted value with the experimental value.

\subsection{Purification Process and Identification of Nimbolide}

Nimbolide extraction was examined with MAE, using the optimum-selected MAE conditions. The solution was filtered and evaporated to dryness. The crude extract was re-extracted in a solid-liquid extraction process with dichloromethane (DCM), to obtain the DCM crude extract. The crude product was purified by preparative thin-layer chromatography (PTLC) plates, using EtOAc/hexane (4:6) as an eluent (Figure 4). The purification process using the PTLC plates was conducted using silica gel (silica gel $60 \mathrm{PF}_{254}$, Merck, Darmstadt, Germany). The spectroscopy technique was recorded by the melting points (Gallenkamp, Manchester, UK). The Fourier transform infrared (FT-IR) spectrum was recorded on a PerkinElmer (model Spectrum RX I, Waltham, MA, USA) in reciprocal centimeters $\left(\mathrm{cm}^{-1}\right)$. The ${ }^{1} \mathrm{H}$ and ${ }^{13} \mathrm{C}$ NMR experiments were performed by spectrometers (model DRX $400 \mathrm{MHz}$, Bruker, Billerica, $\mathrm{MA}$ ) in $\mathrm{CDCl}_{3}$. Chemical shifts were represented as $\delta$-values in parts per million (ppm), downfield from tetramethyl silane (TMS: $\delta 0.00)$ and relative to residue $\mathrm{CHCl}_{3}$ as the internal reference $\left({ }^{1} \mathrm{H}: \delta 7.26\right.$, $\left.{ }^{13} \mathrm{C}: \delta 77.00\right)$, and the coupling constants ( values) were reported in Hertz $(\mathrm{Hz})$. The peak multiplicities were represented as singlet (s), doublet (d), triplet $(\mathrm{t})$, doublet of doublets (dd), and doublet of a triplet $(\mathrm{dt})$. The structure elucidation of nimbolide was achieved according to their spectral data, including 
FT-IR, ${ }^{1} \mathrm{H}$ NMR, and ${ }^{13} \mathrm{C}$ NMR. The final structures of nimbolide were established by comparing the spectroscopic analysis of the standard, combined with the previous report data.

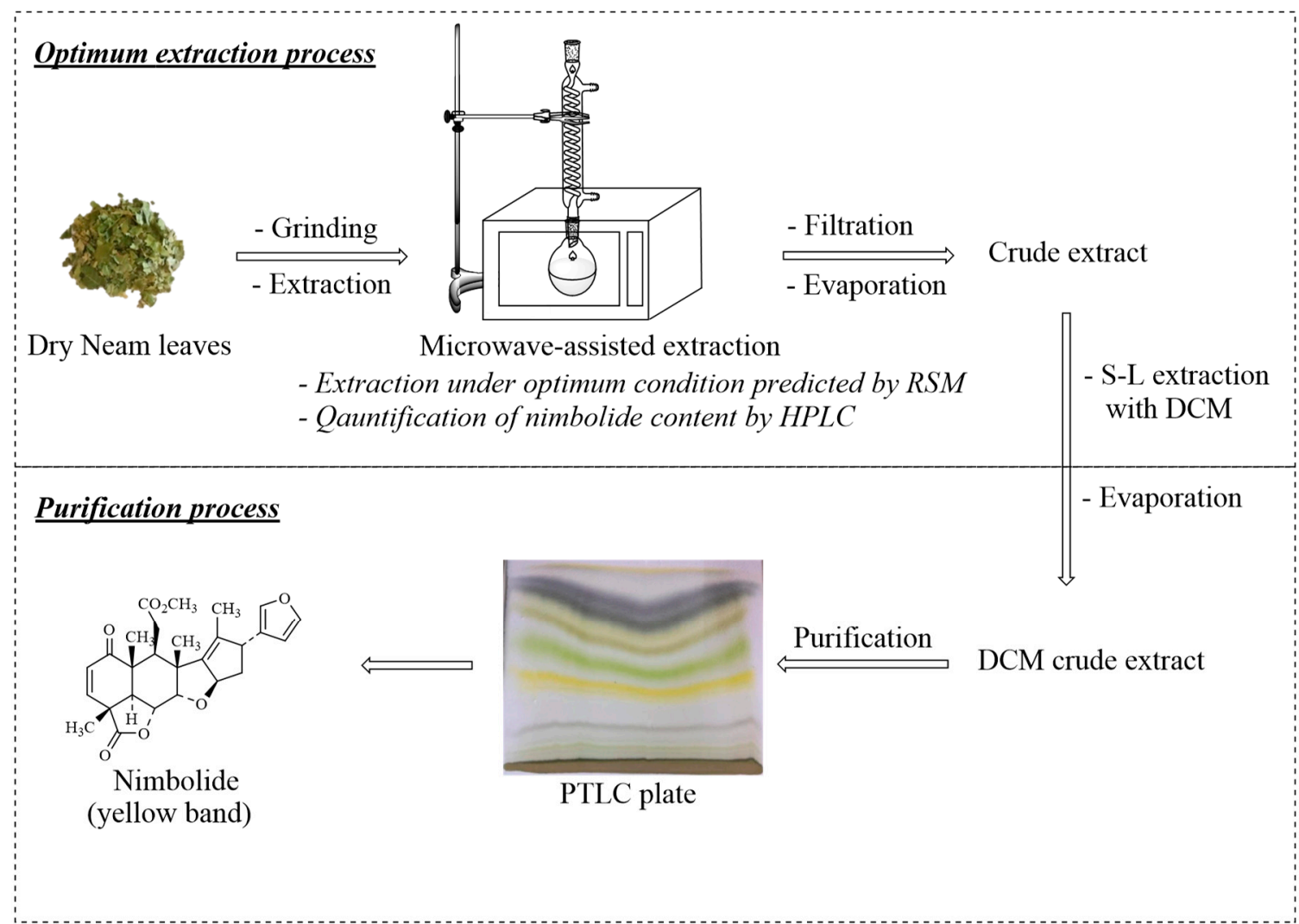

Figure 4. The extraction and purification process of nimbolide.

The characterization of nimbolide (isolated) used the IR and NMR technique. Figure 5 shows the IR spectra of the nimbolide and the chemical structure of nimbolide. Figure 6 shows ${ }^{1} \mathrm{H}$ - and ${ }^{13} \mathrm{C}-\mathrm{NMR}$ spectrum of nimbolide. The main characterization list of nimbolide was as follows: yellow solids, m.p. 120.8-122.3 ${ }^{\circ} \mathrm{C}$, FT-IR Spectrum (KBr); $\left(\lambda \max , \mathrm{cm}^{-1}\right)$ : 3050, 2980, 1775, 1725, 1675, 1438, $953 .{ }^{1} \mathrm{H}-\mathrm{NMR}$ $\left(400 \mathrm{MHz}, \mathrm{CDCl}_{3}, \delta, \mathrm{ppm}, J / \mathrm{Hz}\right): 1.23(\mathrm{~s}, 3 \mathrm{H}), 1.37(\mathrm{~s}, 3 \mathrm{H}), 1.48(\mathrm{~s}, 3 \mathrm{H}), 1.71(\mathrm{~d}, J=1.8 \mathrm{~Hz}, 3 \mathrm{H}), 2.12(\mathrm{dt}$, $J=12.1,8.4 \mathrm{~Hz}, 1 \mathrm{H}), 2.22(\mathrm{dd}, J=12.1,6.7 \mathrm{~Hz}, 1 \mathrm{H}), 2.38(\mathrm{dd}, J=16.2,5.8 \mathrm{~Hz}, 1 \mathrm{H}), 2.74(\mathrm{t}, J=5.6 \mathrm{~Hz}$, $1 \mathrm{H}), 3.18(\mathrm{~d}, J=12.5 \mathrm{~Hz}, 1 \mathrm{H}), 3.25(\mathrm{dd}, J=16.2,5.3 \mathrm{~Hz}, 1 \mathrm{H}), 3.54(\mathrm{~s}, 3 \mathrm{H}), 3.67(\mathrm{~d}, J=8.2 \mathrm{~Hz}, 1 \mathrm{H}), 4.27(\mathrm{~d}$, $J=3.7 \mathrm{~Hz}, 1 \mathrm{H}), 4.64(\mathrm{dd}, J=12.5,3.7 \mathrm{~Hz}, 1 \mathrm{H}), 5.53(\mathrm{tp}, J=5.6,1.8 \mathrm{~Hz}, 1 \mathrm{H}), 5.93(\mathrm{~d}, J=9.7 \mathrm{~Hz}, 1 \mathrm{H})$, $6.26(\mathrm{dd}, J=1.9,0.9 \mathrm{~Hz}, 1 \mathrm{H}), 7.22(\mathrm{~s}, 1 \mathrm{H}), 7.28(\mathrm{~d}, J=9.7 \mathrm{~Hz}, 1 \mathrm{H}), 7.32(\mathrm{t}, J=1.7 \mathrm{~Hz}, 1 \mathrm{H}) .{ }^{13} \mathrm{C}-\mathrm{NMR}$ (100 MHz, $\mathrm{CDCl}_{3}, \delta$, ppm): 12.89, 15.15, 17.16, 18.54, 32.14, 41.11, 41.22, 43.65, 45.27, 47.73, 49.47, 50.30, 51.76, 73.43, 82.88, 88.43, 110.32, 126.53, 131.01, 136.42, 138.87, 143.13, 144.78, 149.59, 172.96, 174.97, 200.80. The spectroscopic data of nimbolide (isolated) were in agreement with those of the nimbolide standard and previously reported data [36]. 


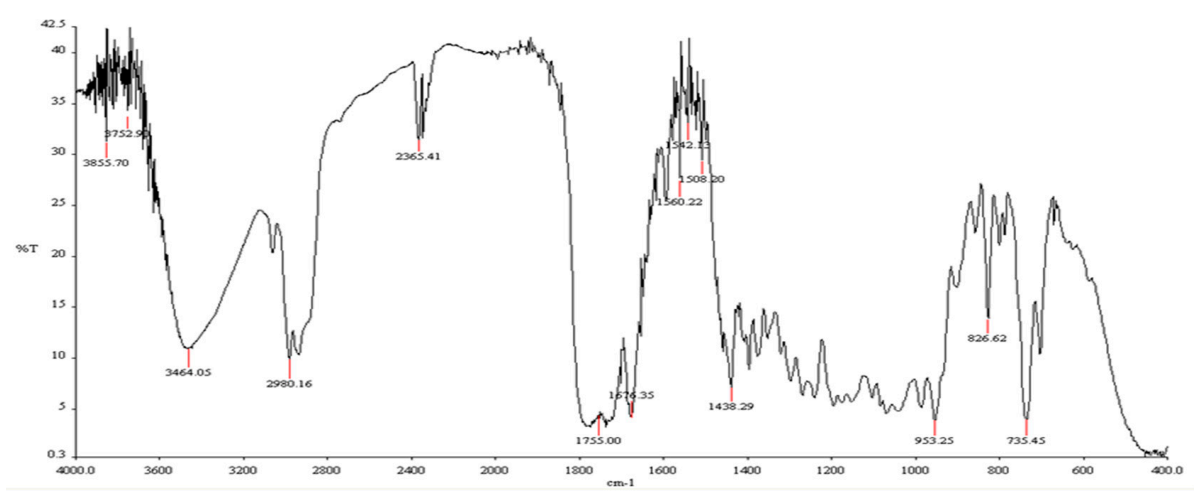

Figure 5. FT-IR spectrum data of nimbolide (isolated).

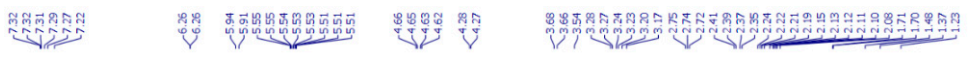

(A)

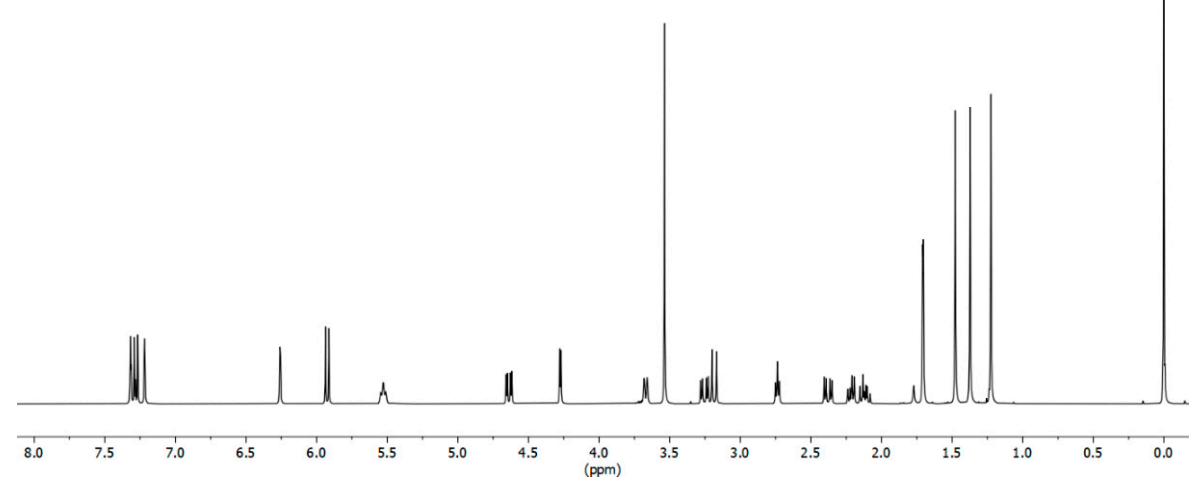

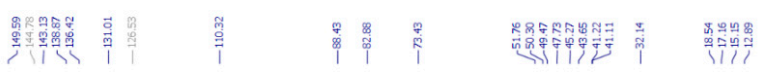

(B)

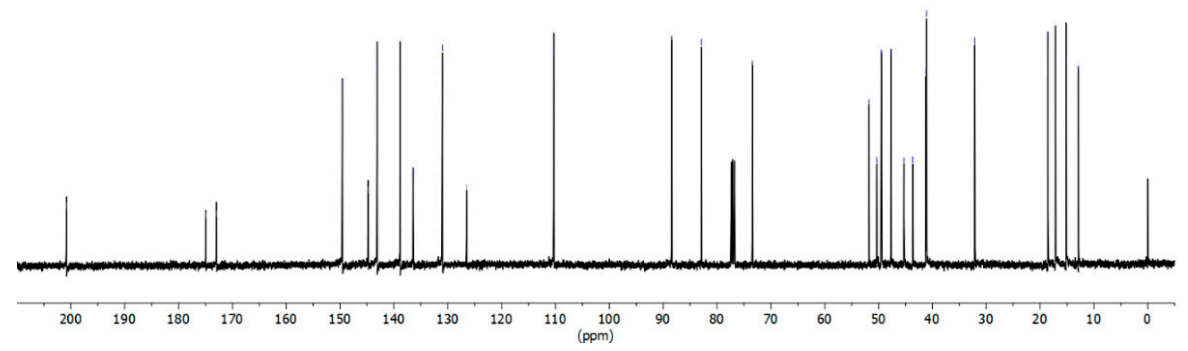

Figure 6. (A) ${ }^{1} \mathrm{H}$ - and (B) ${ }^{13} \mathrm{C}-\mathrm{NMR}$ spectrum of nimbolide (isolated). 


\section{Conclusions}

Microwave-assisted extraction was accomplished by the extraction of the enriched nimbolide product from Azadirachta indica A. Juss. An optimization strategy using response surface methodology based on the Box-Behnken design was successfully applied to optimize extraction with the following parameters-solid/liquid ratio $1: 16 \mathrm{~g} / \mathrm{mL}$, microwave power $280 \mathrm{~W}$, and extraction time $22 \mathrm{~min}$. Under the optimal MAE conditions, the extraction that showed the highest nimbolide yield was $7.243 \mathrm{mg} / \mathrm{g}$ dry weight. The enriched nimbolide crude extract obtained from MAE could simply be isolated by preparative thin-layer chromatography (PTLC) with EtOAc/hexane $=4: 6$. The 0.0336 $\mathrm{g}$ of nimbolide was obtained from $5.00 \mathrm{~g}$ of the neem leaf sample by purifying over $98 \%$ within $3.0 \mathrm{~h}$. These results revealed a new method to improve the processes of extraction and purification of nimbolide, which were simple, fast, and efficient. This procedure has a good potential for the preparation of an anticancer compound from a medicinal plant for pharmaceutical applications.

Author Contributions: Conceptualization, P.S. and V.C.; methodology, V.C.; software, P.S.; investigation, P.S. and V.C.; writing - original draft preparation, P.S.; writing-review and editing, P.S. and V.C.; supervision, V.C.; funding acquisition, V.C. All authors have read and agreed to the published version of the manuscript.

Funding: We would like to thank The Thailand Research Fund (TRF) TRG5780146 for their financial support.

Acknowledgments: This research was supported by the Center of Excellence in Agricultural Innovation for Graduate Entrepreneur, Maejo University, Chiang Mai, Thailand. We also thank Pittayaporn Boontakham for sharing their expertise in the quantification process.

Conflicts of Interest: The authors declare no conflict of interest.

\section{References}

1. Sarah, R.; Tabassum, B.; Idrees, N.; Hussain, M.K. Bio-active Compounds Isolated from Neem Tree and Their Applications. Nat. Bio-Act. Compd. 2019, 509-528. [CrossRef]

2. Kumar, V.S.; Navaratnam, V.; Ravichandran, V. Neem (Azadirachta indica): Prehistory to contemporary medicinal uses to humankind. Asian Pac. J. Trop. Biomed. 2013, 3, 505-514. [CrossRef]

3. Biswas, K.; Chattopadhyay, I.; Banerjee, R.K.; Bandyopadhyay, U. Biological activities and medicinal properties of neem (Azadirachta indica). Curr. Sci. Bangalore 2002, 82, 1336-1345.

4. Drabu, S.; Khatri, S.; Babu, S. Neem: Healer of all ailments. Res. J. Pharm. Biol. Chem. Sci. 2012, 3, $120-126$.

5. Alzohairy, M. Therapeutics Role ofAzadirachta indica(Neem) and Their Active Constituents in Diseases Prevention and Treatment. Evid.-Based Complement. Altern. Med. 2016, 2016, 1-11. [CrossRef]

6. Rahmani, A.H.; Almatroudi, A.; AlRumaihi, F.; Khan, A.A. Pharmacological and therapeutic potential of neem (Azadirachta indica). Pharmacogn. Rev. 2018, 12, 250. [CrossRef]

7. Baira, S.M.; Khurana, A.; Somagoni, J.; Srinivas, R.; Godugu, C.; Talluri, M.K. First report on the pharmacokinetic profile of nimbolide, a novel anticancer agent in oral and intravenous administrated rats by LC/MS method. J. Chromatogr. B 2018, 1092, 191-198. [CrossRef]

8. Elumalai, P.; Gunadharini, D.; Senthilkumar, K.; Banudevi, S.; Arunkumar, R.; Benson, C.; Sharmila, G.; Arunakaran, J. Induction of apoptosis in human breast cancer cells by nimbolide through extrinsic and intrinsic pathway. Toxicol. Lett. 2012, 215, 131-142. [CrossRef] [PubMed]

9. Gupta, S.C.; Prasad, S.; Sethumadhavan, D.R.; Nair, M.S.; Mo, Y.-Y.; Aggarwal, B.B. Nimbolide, a limonoid triterpene, inhibits growth of human colorectal cancer xenografts by suppressing the proinflammatory microenvironment. Clin. Cancer Res. 2013, 19, 4465-4476. [CrossRef] [PubMed]

10. Farooqui, N.A.; Dey, A.; Singh, G.; Easwari, T. Antibacterial potential of nimbolide from Azadirachta indica. Int. J. Pharm. Pharm. Sci. 2014, 6, 636-638.

11. Suresh, G.; Gopalakrishnan, G.; Wesley, S.D.; Singh, N.D.P.; Malathi, R.; Rajan, S.S. Insect Antifeedant Activity of Tetranortriterpenoids from the Rutales. A Perusal of Structural Relations. J. Agric. Food Chem. 2002, 50, 4484-4490. [CrossRef] [PubMed]

12. Sithisarn, P.; Supabphol, R.; Gritsanapan, W. Antioxidant activity of Siamese neem tree (VP1209). J. Ethnopharmacol. 2005, 99, 109-112. [CrossRef] [PubMed] 
13. Huie, C.W. A review of modern sample-preparation techniques for the extraction and analysis of medicinal plants. Anal. Bioanal. Chem. 2002, 373, 23-30. [CrossRef] [PubMed]

14. Sithisarn, P.; Supabphol, R.; Gritsanapan, W. Comparison of Free Radical Scavenging Activity of Siamese Neem Tree (Azadirachta indica A. Juss var. siamensis Valeton) Leaf Extracts Prepared by Different Methods of Extraction. Med. Princ. Pr. 2006, 15, 219-222. [CrossRef]

15. Sultana, B.; Anwar, F.; Ashraf, M. Effect of Extraction Solvent/Technique on the Antioxidant Activity of Selected Medicinal Plant Extracts. Molecules 2009, 14, 2167-2180. [CrossRef] [PubMed]

16. Patel, M.J.; Tripathy, S.; Mukhopadhyay, K.D.; Wangjam, T.; Cabang, A.B.; Morris, J.; Wargovich, M.J. A supercritical CO2 extract of neem leaf (A. indica ) and its bioactive liminoid, nimbolide, suppresses colon cancer in preclinical models by modulating pro-inflammatory pathways. Mol. Carcinog. 2018, 57, 1156-1165. [CrossRef]

17. Pinela, J.; Prieto, M.A.; Carvalho, A.M.; Barreiro, M.F.; Oliveira, M.B.P.P.; Barros, L.; Ferreira, I.C.F.R.; Barreiro, M.F. Microwave-assisted extraction of phenolic acids and flavonoids and production of antioxidant ingredients from tomato: A nutraceutical-oriented optimization study. Sep. Purif. Technol. 2016, 164, 114-124. [CrossRef]

18. Dai, J.; Yaylayan, V.A.; Raghavan, G.S.V.; Paré, J.R.J.; Liu, Z.; Bélanger, J.M.R. Influence of operating parameters on the use of the microwave-assisted process (MAP) for the extraction of azadirachtin-related limonoids from neem (Azadirachta indica) under atmospheric pressure conditions. J. Agric. Food Chem. 2001, 49, 4584-4588. [CrossRef] [PubMed]

19. Nde, D.B.; Boldor, D.; Astete, C. Optimization of microwave assisted extraction parameters of neem (Azadirachta indica A. Juss) oil using the Doehlert's experimental design. Ind. Crop. Prod. 2015, 65, $233-240$. [CrossRef]

20. Bagade, S.B.; Patil, M. Recent Advances in Microwave Assisted Extraction of Bioactive Compounds from Complex Herbal Samples: A Review. Crit. Rev. Anal. Chem. 2019, 1-12. [CrossRef] [PubMed]

21. Suttiarporn, P.; Wongkattiya, N.; Buaban, K.; Poolprasert, P.; Tanruean, K. Process Optimization of Microwave Assisted Simultaneous Distillation and Extraction from Siam cardamom using Response Surface Methodology. Process. 2020, 8, 449. [CrossRef]

22. Wang, L.; Lu, W.; Li, J.; Hu, J.; Ding, R.; Lv, M.; Wang, Q. Optimization of Ultrasonic-Assisted Extraction and Purification of Zeaxanthin and Lutein in Corn Gluten Meal. Molecules 2019, 24, 2994. [CrossRef]

23. Le, X.D.; Nguyen, M.C.; Vu, D.H.; Pham, M.Q.; Pham, Q.L.; Nguyen, Q.T.; Nguyen, T.A.; Pham, V.T.; Bach, L.G.; Van Nguyen, T.; et al. Optimization of Microwave-Assisted Extraction of Total Phenolic and Total Flavonoid Contents from Fruits of Docynia indica (Wall.) Decne. Using Response Surface Methodology. Processes 2019, 7, 485. [CrossRef]

24. Tian, S.; Hao, C.; Xu, G.; Yang, J.; Sun, R. Optimization conditions for extracting polysaccharide from Angelica sinensis and its antioxidant activities. J. Food Drug Anal. 2017, 25, 766-775. [CrossRef] [PubMed]

25. Assunção, P.I.D.; Da Conceição, E.C.; Borges, L.L.; De Paula, J.A.M. Development and Validation of a HPLC-UV Method for the Evaluation of Ellagic Acid in Liquid Extracts of Eugenia uniflora L. (Myrtaceae) Leaves and Its Ultrasound-Assisted Extraction Optimization. Evid.-Based Complement. Altern. Med. 2017, 2017, 1-9. [CrossRef]

26. Gan, C.-Y.; Latiff, A.A. Optimisation of the solvent extraction of bioactive compounds from Parkia speciosa pod using response surface methodology. Food Chem. 2011, 124, 1277-1283. [CrossRef]

27. Zhang, H.-F.; Yang, X.-H.; Wang, Y. Microwave assisted extraction of secondary metabolites from plants: Current status and future directions. Trends Food Sci. Technol. 2011, 22, 672-688. [CrossRef]

28. Radojković, M.; Zeković, Z.; Jokić, S.; Vidović, S.; Lepojević, Ž.; Milošević, S. Optimization of solid-liquid extraction of antioxidants from black mulberry leaves by response surface methodology. Food Technol. Biotechnol. 2012, 50, 167-176.

29. Qin, S.; Lv, C.; Wang, Q.; Zheng, Z.; Sun, X.; Tang, M.; Deng, F. Extraction, identification, and antioxidant property evaluation of limonin from pummelo seeds. Anim. Nutr. 2018, 4, 281-287. [CrossRef]

30. Filip, S.; Pavlić, B.; Vidovic, S.; Vladić, J.; Zeković, Z. Optimization of Microwave-Assisted Extraction of Polyphenolic Compounds from Ocimum basilicum by Response Surface Methodology. Food Anal. Methods 2017, 10, 2270-2280. [CrossRef] 
31. Le, X.T.; Vi, V.L.L.; Toan, T.Q.; Bach, L.G.; Truc, T.T.; Ha, P.T.H. Extraction Process of Polyphenols from Soybean (Glycine max L.) Sprouts: Optimization and Evaluation of Antioxidant Activity. Processes 2019, 7, 489. [CrossRef]

32. Dhobi, M.; Mandal, V.; Hemalatha, S. Optimization of microwave assisted extraction of bioactive flavonolignan-silybinin. J. Chem. Metrol. 2009, 3, 13-23.

33. Mendes, M.; Carvalho, A.; Magalhaes, J.M.; Moreira, M.M.; Guido, L.; Gomes, A.M.; Delerue-Matos, C. Response surface evaluation of microwave-assisted extraction conditions for Lycium barbarum bioactive compounds. Innov. Food Sci. Emerg. Technol. 2016, 33, 319-326. [CrossRef]

34. Lu, Z.; Muhammad, U.; Zhu, X.; Han, J.; Sun, J.; Tayyaba, S.; Abbasi, B.; Siyal, F.A.; Dhama, K.; Saqib, J. Effects of Extraction Variables on Pharmacological Activities of Vine Tea Extract (Ampelopsis grossedentata). Int. J. Pharmacol. 2018, 14, 495-505. [CrossRef]

35. Chen, F.; Du, X.; Zu, Y.; Yang, L.; Wang, F. Microwave-assisted method for distillation and dual extraction in obtaining essential oil, proanthocyanidins and polysaccharides by one-pot process from Cinnamomi Cortex. Sep. Purif. Technol. 2016, 164,1-11. [CrossRef]

36. Kigodi, P.G.K.; Blaskó, G.; Thebtaranonth, Y.; Pezzuto, J.M.; Cordell, G.A. Spectroscopic and Biological Investigation of Nimbolide and 28-Deoxonimbolide from Azadirachta indica. J. Nat. Prod. 1989, 52, 1246-1251. [CrossRef]

37. Nair, M.S.; Gopal, S.; Issac, D. Optimised isolation procedure for biologically active compounds nimbolide and 28-deoxonimbolide from Azadirachta indica leaves. Phytochemistry 1997, 46, 1177-1178. [CrossRef]

38. Dhanya, S.R.; Kumar, S.N.; Sankar, V.; Raghu, K.G.; Nair, M.S. Nimbolide from Azadirachta indica and its derivatives plus first-generation cephalosporin antibiotics: A novel drug combination for wound-infecting pathogens. RSC Adv. 2015, 5, 89503-89514. [CrossRef]

Sample Availability: Samples of the compounds are not available from the authors.

(C) 2020 by the authors. Licensee MDPI, Basel, Switzerland. This article is an open access article distributed under the terms and conditions of the Creative Commons Attribution (CC BY) license (http://creativecommons.org/licenses/by/4.0/). 